\title{
Health for all? Dream on!
}

In 1978 the international community in Alma-Ata committed itself to the slogan 'Health for all by the year 2000'. ${ }^{1}$ Thirty years later many are still deprived of the basic right of health. Several factors block the road that leads to 'health for all'. This article examines the factors that makes 'health for all' a far-fetched possibility if possible at all.

The World Health Organization (WHO) maintains that 'Health is a state of complete physical, mental and social wellbeing and not merely the absence of disease'. ${ }^{1}$ Keeping this in mind it may be misleading to assume that increased lifeexpectancy or better income implies improvement in quality of life. It is estimated that $30 \%$ of the population of the world is affected by mental illness every year. The majority of those with mental illness do not receive adequate treatment; this is not just the case in poor countries but also applies to affluent societies. ${ }^{2}$ Proper sanitation is one of the most effective health measures that decrease mortality and morbidity; yet $40 \%$ of the world's population lacks access to toilets and a proper sewage system. ${ }^{3}$

Drug manufacturers invent valuable remedies. Occasionally, the pharmaceutical industry practices result in irrational practices. Pharmaceutical companies also spend more money on promotion than on research and development. ${ }^{4}$ These marketing efforts alter physician's prescription behaviour. ${ }^{5}$ Doctors' failure to adhere to sound medical practice can also result in great financial losses; a recent report highlighted that the misuse of one proton pump inhibitor by doctors results in unnecessary expenditure in the UK and the world, amounting to a $£ 100$ million and £2 billion, respectively. ${ }^{6}$

Conflict of interest constitutes the major violation to ethical standards. Some thought leaders in Lebanon, who run research for vaccine manufacturers and travel at their expense, pass unsound recommendation to immunise children with the expensive varicella vaccine at a time when more than $85 \%$ of Lebanese adolescents are naturally immune to chicken pox. ${ }^{7}$ Some researchers have even expressed concerns about the financial relationship between the drug industry and members on institutional review boards. ${ }^{8}$

The WHO has made several positive contributions. These contributions seem to vary from one region to another. In the EMR (Eastern Mediterranean Region), the WHO's lack of continuity and ability to affect decision makers in a positive way contributes to slowing the pace towards accessible and affordable health for the vast under-privileged populations of the EMR. In 1999 the WHO hosted an InterCountry Consultation on family practice in Manama, Bahrain and came up with good recommendations that were not followed up. In 2007 the WHO-EMR called for another 'First Inter-Country Consultation on Family Practice' in Sana, Yemen. Once the representatives of the countries departed there was no follow-up on the issued recommendations. The representatives in these meetings were mainly nominated by their governments. It is not unusual that such nominations are based on political grounds rather than competency in the discipline of general practice. Lack of continuous commitment to primary care by the $\mathrm{WHO}$ has been previously reported. ${ }^{9}$

The WHO function, as stated in its constitution is 'to assist governments, upon request, in strengthening health services'. ${ }^{10}$ This implies that assistance will be delivered if a government makes a request. Only three of the 18 countries represented in the Sana meeting reported to have a national programme to develop family practice. ${ }^{11}$ The WHO failure to make substantial progress in the field of primary care in the EMR may be attributed to having weak partners; partners who signed the Alma-Ata declaration but did not act on it after 30 years.

The WHO constitution mentions collaboration with 'professional groups and such other organizations as may be deemed appropriate'. ${ }^{10}$ But when such bodies do not exist or are simply dictated to by governments that are not committed to primary care, the $\mathrm{WHO}$ is left alone listening only to the echo of its voice.

The truth is that we are still far from 'Health for all'. Yet, the pursuit of the dream will keep some of us alive even if we do not catch up with it.

\section{Bassem Saab}

\section{REFERENCES}

1. Declaration of Alma-Ata International Conference on Primary Health Care, Alma-Ata, USSR, 6-12 September 1978.

http://www.who.int/hpr/NPH/docs/declaration_alma ata.pdf (accessed 5 Dec 2008)

2. Wang PS, Aquilar-Gaxiola S, Alonso J, et al. Use of mental health services for anxiety, mood, and substance disorders in 17 countries in the WHO world mental health surveys. Lancet 2007; 370 : 841-850.

3. Enviromental Health. Access to toilets for all. Environmental Health at USAID, Virginia, US. http://www.ehproject.org/PDF/ehkm/lancetaccess_toilets2007.pdf (accessed 8 Dec 2008).

4. Gagnon MA, Lexchin J. The cost of pushing pills: a new estimate of pharmaceutical promotion expenditures in the United States. PLoS Med 2008; 5(1): el.

5. Godlee F. Doctors and the drug industry. BMJ 2008; 336(7634): doi:10.1136/bmj.39444.472708.47.

6. Forgacs I, Loganayagam A. Overprescribing protonpump inhibitors. BMJ 2008; 336(7634): 2-3.

7. Musharrafieh UM, Nuwayhid IA, Hamadeh GN, et al. Immunity to chickenpox among school adolescents in Lebanon and options for vaccination. Epidemiol Infect 2002; 129(3): 607-615.

8. Campell EG, Weissman JS, Vogeli C, et al. Financial relationships between institutional review board members and industry. N Engl J Med 2006; 355: 2321-2329.

9. Haines A, Horton R, Bhutta Z. Primary health care comes of age. Looking forward to the 30th anniversary of Alma-Ata: call for papers. Lancet 2007; 370: 911-913.

10. WHO-Constitution - the first two chapters. Geneva: WHO, 1985. http://www.ldb.org/iphw/whoconst.htm (accessed 5 Dec 2008).

11. World Health Organization. Report on the inter country consultation on family practice in the Eastern Mediterranean Region. Geneva: WHO, 2007.

DOI: 10.3399/bjgp09X394923 